\title{
Don't stop walking: the in-home rehabilitation program for peripheral artery disease patients during the COVID-19 pandemic
}

\author{
Nicola Lamberti ${ }^{1}$ - Sofia Straudi ${ }^{2} \cdot$ Roberto Manfredini $^{3}$ (D) Alfredo De Giorgi $^{3}$ - Vincenzo Gasbarro ${ }^{4}$. \\ Paolo Zamboni ${ }^{5} \cdot$ Fabio Manfredini $^{1,2}$
}

Received: 28 September 2020 / Accepted: 2 December 2020 / Published online: 7 January 2021

๑) Springer Nature Switzerland AG part of Springer Nature 2021

\begin{abstract}
We studied the outcomes of peripheral artery disease (PAD) patients enrolled in a structured in-home walking program right before the lockdown due to the SARS-CoV-2 epidemic emergency, to determine whether this intervention ensured the maintenance of mobility even in the case of movement restrictions.

We selectively studied 83 patients (age $72 \pm 11$, males $n=65$ ) enrolled in the program within 9-month before the lockdown. The usual intervention was based on two daily 8-min sessions of slow intermittent in-home walking prescribed in circamonthly hospital visits. During the lockdown, the program was updated by phone. Six-minute (6MWD) and pain-free walking distance (PFWD) were measured pre- and post-lockdown as well as body weight (BW), blood pressure (BP), and anklebrachial index (ABI). Sixty-six patients were measured $117 \pm 23$ days after their previous visit. A safe, pain-free execution of the prescribed sessions was reported (median distance: $74 \mathrm{~km}$ ). Overall, the 6MWD was stable, while PFWD improved $(p<0.001)$. The improvement was not related to age/gender, comorbidities, type of home but to the time of enrollment before lockdown. The new-entry subjects ( $\leq 3$ months; $n=35$ ) obtained significant improvements post-lockdown for $6 \mathrm{MWD}$ and PFWD, while those previously enrolled ( $>3$ months; $n=31$ ) were stable. Decreased BW with stable BP and ABI values were also recorded, with better outcomes for new-entry subjects. In PAD patients, a structured walking program performed inside home and purposely guided by phone was adhered to by patients and favored mobility and risk factor control during the COVID-19 pandemic, regardless of walking ability, type of home and external conditions.
\end{abstract}

Keywords Exercise $\cdot$ Peripheral artery disease $\cdot$ Cardiovascular diseases $\cdot$ Rehabilitation $\cdot$ Risk factors $\cdot$ Mobility

\section{Introduction}

Supplementary Information The online version contains supplementary material available at https://doi.org/10.1007/s1173 9-020-02598-4.

Roberto Manfredini

roberto.manfredini@unife.it

1 Department of Neuroscience and Rehabilitation, University of Ferrara, Ferrara, Italy

2 Rehabilitation Medicine Unit, University Hospital of Ferrara, Ferrara, Italy

3 Department of Medical Sciences, Clinical Medicine Unit, University Hospital of Ferrara, University of Ferrara, via Aldo Moro 8, 44123 Cona, Ferrara, Italy

4 Department of Medical Sciences, Vascular Surgery Unit, University of Ferrara, Ferrara, Italy

5 Department of Morphology, Surgery and Experimental Medicine, University of Ferrara, Ferrara, Italy
More than 202 million people are living with PAD, and of these, a high percentage includes elderly individuals [1]. PAD affects functional status by evoking classic claudication or atypical exertional leg symptoms by favoring functional impairment and decline in asymptomatic subjects $[1,2]$.

Structured exercise, with supervised exercise being preferred and more effective [3], is part of a comprehensive program to manage disability and cardiovascular risk [4]; however, in recent years, various home-based structured programs have been proposed [2] based on indoor [5, 6] or outdoor (guided or assisted by wearable technologic devices, etc.) walking [2,7-9] not always with proven effectiveness [9].

Recently, the COVID-19 epidemic emergency has seriously limited the possibility of attending in-hospital supervised exercise, performing outdoor structured home-based 
programs and taking spontaneous walks [10], particularly in countries where strict movement restrictions have been imposed by the government in an attempt to slow virus transmission $[11,12]$. Italy was the first European country where, from March 9th to May 3rd (55 days), a series of restrictions on citizens' mobility were adopted, including exercise and pet walking being allowed only around the home and a self-declaration form specifying the purpose of their movement and their destination being required [10, 13].

The fear of contagion, particularly present among elderly people, due to the higher percentage of deaths among elderly individuals [14], limited their willingness to leave home to perform physical activity, e.g., to walk for claudication or medical reasons $[15,16]$.

In addition to such dissuading factors, the reduced availability of non-strictly necessary outpatient services and the limited time of practitioners as well as delayed access to treatment $[16,17]$ in a country where the National Healthcare Service offers free universal access to health care, may have triggered a subsequent wave of worsening of functional status and cardiovascular risk factors including glycemic or blood pressure control [18].

Ten years ago, to improve the mobility of PAD patients and to overcome most barriers to exercise in PAD patients, a structured in-home exercise program was developed for PAD $[5,6]$ in an area of the Emilia Romagna Region with a very high aging index [19]. The program, regularly offered to patients with PAD as an outpatient program and successfully tested in stroke survivors and dialysis patients [20-23], is based on bouts of interval walking at progressively increasing speeds that are performed inside the home in a corridor. Only a few controls in the hospital are requested to update the program.

The present study aimed to evaluate the adherence to and the effects of the program in a cohort of elderly patients enrolled right before the lockdown in Italy and assisted by phone during this period. The hypothesis was that a minimum but structured dose of exercise would guarantee functional stability in people deprived of the opportunity to walk freely, considering that in PAD patients a sedentary lifestyle is responsible of a progressive decline of mobility [24].

\section{Methods}

\section{Study design}

This is an observational study that was carried out at the Department of Rehabilitation Medicine at the University Hospital of Ferrara. The Ethics Committee CE-AV approved the study (n. 539/2020) and written informed consent was obtained.

\section{Subjects and inclusion criteria}

All of the patients who were participating in the vascular rehabilitation program, which is part of the care for patients with claudication at University Hospital of Ferrara, at the time of lockdown (March 9th, 2020) were considered eligible for this study. In this study, all patients started the exercise program no more than 9 months before the lockdown date.

Males and females aged $>18$ years with Leriche-Fontaine Stage II vascular claudication that was stable for at least 3 months are usually enrolled, whereas patients with conditions contraindicating safe training execution at home (e.g., unstable angina, severe heart failure, major amputation or clinical conditions limiting exercise testing) are usually excluded. The presence of PAD was previously diagnosed at the Vascular Surgery Unit of the Hospital of Ferrara by clinical and echo-color-Doppler examination [25].

\section{Sample size}

The study would require a sample size of 59 participants to achieve a power of $85 \%$ and a level of significance of $5 \%$ (two sided), for detecting a mean of the differences of $25 \mathrm{~m}$ on $6 \mathrm{~min}$ walking test from the beginning of the rehabilitation program to the post-lockdown visit, assuming the standard deviation of the differences to be $60 \mathrm{~m}$.

\section{Exercise program}

All the patients enrolled were executing the "Test in-Train out" (Ti-To), structured, pain-free home-based exercise program $[5,6]$. Ti-To program includes a center-based phase and a home-based phase with walking exercises. The first phase is composed of circa-monthly visits at the hospital for clinical assessment, hemodynamic and performance measurements, an update of the home-based walking program prescription, and evaluation of patient adherence. The home-based phase includes the execution of training at home, preferably indoors (e.g., hallway, heated garage). The program is based on two daily 8-min walking sessions per day (six days per week) of intermittent walking (1-min work and 1-min seated rest) at a prescribed speed. The training speed, converted into walking cadence (steps/minute), is maintained at home by a metronome as learned in a training session executed during the first visit. The exercise program increases weekly by 3-4 steps/min, from 60 to $92-100$ steps/ min according to the severity of claudication at baseline. Progressively, the length of each bout is amplified with a work:rest ratio from $1: 1$ to $2: 1$ and $3: 1$, while the whole duration of each session remains constant. Patients are asked 
to fill out a daily training diary, indicating completion of the exercise and any related symptoms. The exercise program ends when the patients reach a pain-free walking distance that is normal for their sex and age or when a stable satisfactory performance is attained. Additional details on the exercise program and the training session execution are reported elsewhere [5, 26], https://www.youtube.com/watch ?v=ki8YX_t-0jA].

\section{Outcome measures}

At entry into the program, information regarding clinical status and functional impairment was collected by consulting patients' medical documents, by means of physician examination or by specific tests. Body weight (BW) and height were measured for body mass index (BMI) calculation.

\section{Hemodynamic assessment}

After five minutes of rest, patients underwent ankle-brachial index (ABI) measurements according to a standard procedure using Doppler ultrasound (Dopplex SD2, Huntleigh Healthcare Ltd. Diagnostics, Cardiff, United Kingdom) and a standard blood pressure (BP) cuff. The leg with the lowest ABI value was considered the worst leg. The vessels were considered "not compressible" for ABI measurements $>1.4$. Systolic blood pressure (SBP) and diastolic blood pressure (DBP) were also collected.

\section{Performance assessment}

The 6-min walking test was executed according to the published standard [27]. Patients were instructed to walk back and forth along a $21-\mathrm{m}$ corridor alone at their own pace with the aim of covering as much distance as possible in $6 \mathrm{~min}$. The total distance walked (6-min walking distance, 6MWD) and the pain-free walking distance (PFWD) were recorded.

For this specific study, two time points of collection were considered: the last hospital visit before the lockdown (Pre) and the first return to the hospital after the lockdown (Post).

\section{Program update during the lockdown period}

Considering that the vascular rehabilitation program was closed from March 9th to May 18 2020, the rehabilitation team remained available by phone during the entire period of closure. A team member called all the patients enrolled to check their health status and to update the exercise program. The scheduled training program progression $[5,26]$, was confirmed if the patients reported regular program execution in the absence of general or peripheral symptoms. Otherwise, the progression was delayed in the presence of incomplete execution or limiting symptoms, with the patients being advised to repeat part of the previous program in the following weeks.

In addition, a quick telephone questionnaire was administered to the patients to examine factors related to exercise execution, clinical status and the characteristics of their home. The questionnaire was composed of nine Yes/No questions, which are reported in Table 1.

\section{Statistical analysis}

Data are expressed as the mean \pm standard deviation for continuous data and as the percentage frequency for categorical data.

The entire enrolled PAD population was divided into two subgroups according to the time since they started the rehabilitation program. One subgroup included patients who started the program within the three months prior to the lockdown (Rookies), whereas the other subgroup included all the other patients who were enrolled more than three months (Veterans) before the lockdown. The cutoff was arbitrarily chosen considering an ideal duration of the program of 6-9 months [5] and a timeframe possibly associated with physiological adaptations to the program [26, 28]. Pre versus Post comparisons of all outcomes were performed by paired samples $t$ tests or Wilcoxon rank tests according to the data distribution. The between-subgroup comparisons were performed with chi-squared tests, independent samples $t$ tests or Mann-Whitney tests, as appropriate.

Multiple and logistic regression models were employed to identify any factor potentially related to an increased walking ability by defining the performance variations (PFWD and 6MWD) in the Pre-Post-period, properly dichotomized when needed, as dependent variables. Independent variables included patient characteristics (age, sex and marital status, cultural level), cardiovascular risk factors, comorbidities,

Table 1 The telephone questionnaire and the answers provided by the patients

\begin{tabular}{|c|c|c|}
\hline & Yes $(\%)$ & No $(\%)$ \\
\hline Did you exercise regularly at least once a day? & $59(90)$ & $7(10)$ \\
\hline $\begin{array}{l}\text { Did you execute more exercise sessions respect to } \\
\text { the prescribed ones? }\end{array}$ & $21(32)$ & $45(68)$ \\
\hline Did one of your cohabitant exercise with you? & $9(14)$ & $57(86)$ \\
\hline Did you feel that your claudication is worsened? & $5(8)$ & $61(92)$ \\
\hline Did you gain weight? & $11(17)$ & $55(83)$ \\
\hline Did your blood glucose increase $?^{\dagger}$ & $6(24)$ & $19(76)$ \\
\hline Do you live in the city? & $28(42)$ & $38(58)$ \\
\hline Does your house/building have a garden? & $60(91)$ & $6(9)$ \\
\hline Do you have a dog? & $21(32)$ & $45(68)$ \\
\hline How big is your house? $\left(\mathrm{m}^{2}\right)$ & $86 \pm 21$ & \\
\hline
\end{tabular}

Collected only in the sample of diabetes patients 
hemodynamic severity and functional limitation (ABI, PrePFWD and 6MWD), the day of participation in the program before the lockdown, and the items from the telephone questionnaire.

Statistical analyses were performed with MedCalc Statistical Software version 19.4.0 (MedCalc Software bvba, Ostend, Belgium).

\section{Results}

Sixty-six out of the 83 patients ( $80 \%)$ who were enrolled in the Ti-To exercise program completed the post-lockdown visit and the outcome measurement session. Seventeen patients $(20 \%)$ did not show up at the follow-up evaluation (Fig. 1) for the following reasons: lack of availability ( $n=10,12 \%)$, acute limb ischemia $(n=1,1 \%)$, intercurrent disease, such as low back pain $(n=3,4 \%)$ or hip prosthesis $(n=1,1 \%)$, and death (neoplastic disease and COVID-19, $n=2,2 \%)$. At the post-lockdown, 35 patients belonged to the Rookies subgroup whereas 31 patients to the Veterans subgroup. At baseline, the two subgroups did not present any differences (Table 2).

\section{Telephone questionnaire results and program update}

All patients answered the simple telephone questionnaire in a median time of $5 \mathrm{~min}$. The answers provided by the patients to each question are reported in Table 1. Along with the questionnaire, patients were given the updated program by a team member. No adverse events were reported during execution of the program. Fifty-seven patients (86\%) underwent the program progression as scheduled, whereas the remaining nine patients (14\%), due to an insufficient number of sessions performed or intercurrent problems, were advised to repeat the sequence scheduled in the previous program. Six patients needed to contact the rehabilitation team again during the period for more information about the exercise training.

\section{Outcomes after lockdown}

Patients were subsequently called again starting from May 4,2020 , to reschedule a hospital visit that occurred after 117 (95\% CI 111-123) days after the previous visit.

Patients reported execution of a median of $85 \%$ (95\% CI 77-100) of the prescribed exercise sessions, for a total of $>2100 \mathrm{~min}(35 \mathrm{~h})$. The training time considering a step length of $50 \mathrm{~cm}$, and program execution 6 days/week corresponded to a median of $74 \mathrm{~km}$ walked inside the house during the lockdown period. No adverse events related to execution of the training were reported, and the majority of the walking sessions were executed in the absence of claudication pain.

In the whole population, BW showed a significant decrease, while stable values were observed in BP (Table 3). The ABI of both limbs did not show significant variations in the pre-post period; otherwise, PFWD significantly improved $(p<0.001)$ but not the 6MWD $(p=0.13)$.

Considering the two groups, different responses were observed. The Rookies showed a significant improvement in the ABI of the less impaired limb, SBP, 6MWD, PFWD, and BW; the DPB and ABI of the more impaired limb also showed favorable variations approaching statistical significance $(p<0.10)$.
Fig. 1 Study flow diagram of participants enrolled in the period June 2019-March 2020

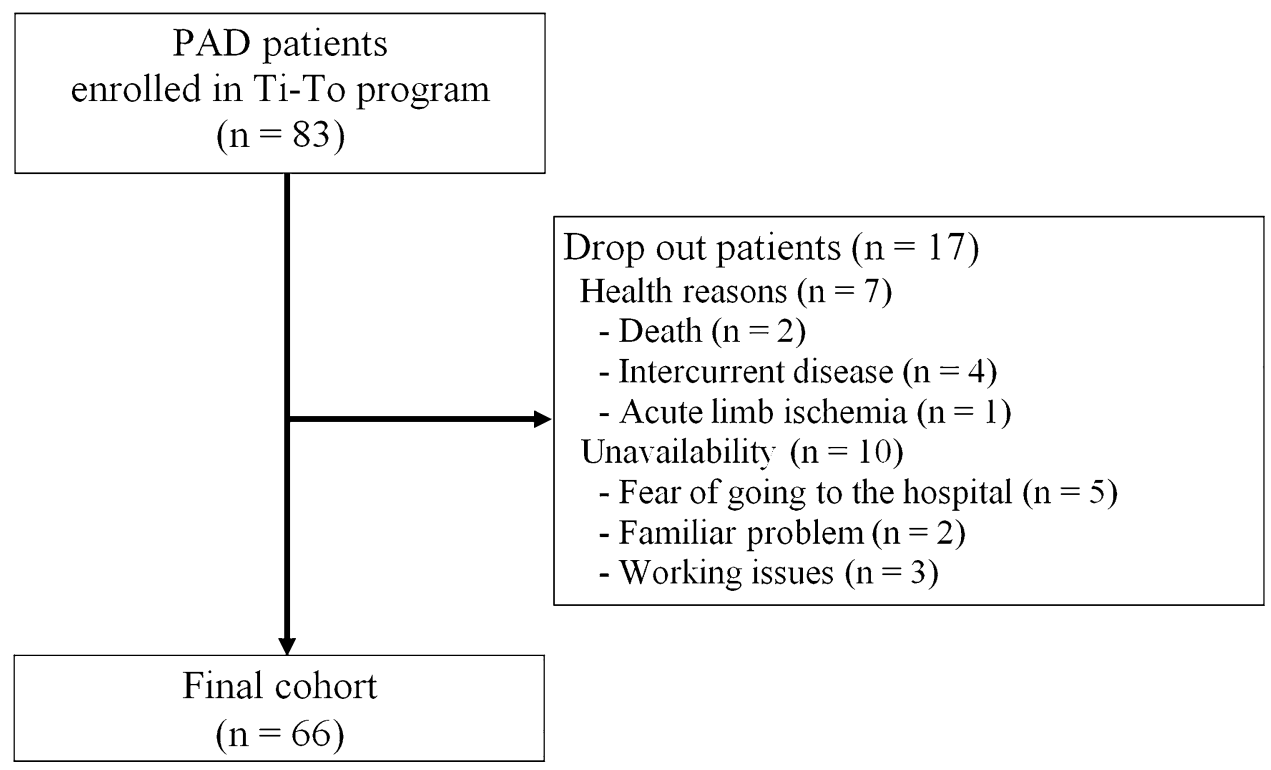


Table 2 Baseline characteristics of the two subgroups of patients

\begin{tabular}{|c|c|c|c|}
\hline & $\begin{array}{l}\text { Rookies } \\
(n=35)\end{array}$ & $\begin{array}{l}\text { Veterans } \\
(n=31)\end{array}$ & $p$ \\
\hline Age (years) & $73 \pm 6$ & $70 \pm 14$ & 0.20 \\
\hline Weight (kg) & $87 \pm 15$ & $85 \pm 18$ & 0.66 \\
\hline BMI $\left(\mathrm{kgm}^{-2}\right)$ & $30 \pm 4$ & $29 \pm 5$ & 0.44 \\
\hline \multicolumn{4}{|l|}{ Education, $n(\%)$} \\
\hline Elementary school & $16(46)$ & $10(32)$ & 0.18 \\
\hline Inferior middle school & $15(43)$ & $9(29)$ & 0.21 \\
\hline Superior middle school & $3(9)$ & $10(32)$ & 0.07 \\
\hline Degree & $1(3)$ & $2(7)$ & 0.41 \\
\hline \multicolumn{4}{|l|}{ Risk factors, $n(\%)$} \\
\hline Smoking & $31(89)$ & $29(94)$ & 0.49 \\
\hline Hypertension & $33(94)$ & $28(91)$ & 0.55 \\
\hline Hyperlipidaemia & $26(74)$ & $21(68)$ & 0.56 \\
\hline Diabetes & $14(40)$ & $11(36)$ & 0.71 \\
\hline Chronic kidney disease & $6(17)$ & $7(23)$ & 0.58 \\
\hline Family history for CVD & $3(9)$ & $6(19)$ & 0.09 \\
\hline \multicolumn{4}{|l|}{ Comorbidities, $n(\%)$} \\
\hline Coronary heart disease & $16(45)$ & $21(68)$ & 0.08 \\
\hline Cerebrovascular disease & $7(20)$ & $3(10)$ & 0.24 \\
\hline Osteoarticular disease & $19(54)$ & $19(61)$ & 0.58 \\
\hline Rheumatic diseases & $5(14)$ & $2(7)$ & 0.30 \\
\hline Age-adjusted Charlson Comorbidity Index & $6 \pm 2$ & $6 \pm 2$ & 0.88 \\
\hline \multicolumn{4}{|l|}{ Pharmacological therapy, $n(\%)$} \\
\hline Antiplatelet & $30(86)$ & $27(87)$ & 0.91 \\
\hline Anticoagulant & $5(14)$ & $4(13)$ & 0.82 \\
\hline \multicolumn{4}{|l|}{ Peripheral artery disease } \\
\hline Disease duration (years) & $5 \pm 5$ & $5 \pm 5$ & 0.89 \\
\hline Lower limb revascularization & $10(28)$ & $8(26)$ & 0.80 \\
\hline Leriche-Fontaine stage $2 \mathrm{a}$ & $24(69)$ & $24(77)$ & 0.57 \\
\hline Leriche-Fontaine stage $2 b$ & $9(31)$ & $9(23)$ & 0.57 \\
\hline ABI more affected limb & $0.64 \pm 0.17$ & $0.65 \pm 0.20$ & 0.76 \\
\hline ABI less affected limb & $0.81 \pm 0.18$ & $0.90 \pm 0.26$ & 0.16 \\
\hline Pain-free walking distance $(\mathrm{m})$, entry & $174 \pm 77$ & $136 \pm 74$ & 0.13 \\
\hline 6-min walking distance $(\mathrm{m})$, entry & $312 \pm 53$ & $285 \pm 91$ & 0.32 \\
\hline Pain-free walking distance (m), Pre & $192 \pm 84$ & $208 \pm 103$ & 0.46 \\
\hline 6-min walking distance (m), Pre & $319 \pm 57$ & $318 \pm 102$ & 0.98 \\
\hline
\end{tabular}

$B M I$ body mass index, $C V D$ cardiovascular disease, $A B I$ Ankle-Brachial Index
The Veterans exhibited stable values for almost all outcomes, while positive variations were obtained for PFWD, though not reaching statistical significance. Data are reported in Table 3.

The between-group comparisons showed that significantly greater variations were observed for the 6MWD and PFWD in favor of the Rookies group (Table 3).

\section{Factors related to favorable performance variations during the lockdown period}

In the whole population, regression analyses were conducted to determine whether any health-related factor or social parameter examined through the telephone questionnaire could be related to a favorable performance. 
Table 3 Within- and between-subgroup differences in rehabilitation outcomes

\begin{tabular}{|c|c|c|c|c|c|c|c|}
\hline & \multicolumn{2}{|l|}{$\begin{array}{l}\text { Whole population } \\
(n=66)\end{array}$} & \multicolumn{2}{|l|}{$\begin{array}{l}\text { Rookies } \\
(\mathrm{n}=35)\end{array}$} & \multicolumn{2}{|l|}{$\begin{array}{l}\text { Veterans } \\
(\mathrm{n}=31)\end{array}$} & \multirow[t]{2}{*}{$p$ between-group } \\
\hline & Pre & Post & Pre & Post & Pre & Post & \\
\hline Weight (kg) & $86(82-90)$ & $85(81-89) *$ & $87(82-92)$ & $86(81-91)^{*}$ & $85(79-91)$ & $84(78-91)$ & 0.64 \\
\hline $\mathrm{SBP}(\mathrm{mmHg})$ & $147(142-151)$ & 145 (141-149) & $151(144-158)$ & $147(141-153)^{*}$ & $142(136-147)$ & $143(138-149)$ & 0.031 \\
\hline DBP (mmHg) & $76(74-78)$ & $74(72-76)$ & $76(73-80)$ & $74(71-77)$ & $75(73-78)$ & $74(71-77)$ & 0.39 \\
\hline ABI worst limb & $0.64(0.59-0.69)$ & $0.65(0.60-0.70)$ & $0.63(0.57-0.70)$ & $0.66(0.59-0.73)$ & $0.65(0.58-0.63)$ & $0.64(0.56-0.72)$ & 0.08 \\
\hline ABI best limb & $0.85(0.79-0.91)$ & $0.87(0.80-0.94)$ & $0.81(0.74-0.88)$ & $0.86(0.78-0.94)^{*}$ & $0.90(0.79-1.00)$ & $0.89(0.77-1.01)$ & 0.07 \\
\hline PFWD (m) & $200(177-222)$ & $227(201-252)^{*}$ & $192(163-221)$ & $230(199-262)^{*}$ & 209 (171-246) & $223(180-265)$ & 0.023 \\
\hline 6MWD (m) & $318(298-338)$ & $323(302-344)$ & 319 (299-338) & $332(311-352)^{*}$ & $318(281-355)$ & $319(271-366)$ & 0.007 \\
\hline
\end{tabular}

Data are expressed as mean and $95 \%$ Confidence Interval

$A B I$ Ankle-Brachial Index, $S B P$ systolic blood pressure, $D B P$ diastolic blood pressure, $P F W D$ pain-free walking distance, $6 M W D$ 6-min walking distance

*Within-group $p$ value $<0.05$ obtained with paired-samples $t$ test or Wilcoxon test. Between group comparison in changes analysed with independent samples $t$ test or Mann-Whitney test

Multiple regressions identified that in a weak model $\left(R^{2}=0.14 ; p=0.031\right)$, only the Pre values of the 6MWD and the days from the entry to the pre-lockdown visit were inversely related to variations in the pre-post period. A similar model was observed for PFWD variations $\left(R^{2}=0.18\right.$; $p=0.022$ ), including PFWD-Pre values and again the time elapsed from the entry to the pre-lockdown visit; both parameters presented negative correlations.

In the logistic regression models, the PFWD and 6MWD variations were dichotomized according to variation equal or greater to the MCID, which is $36 \mathrm{~m}$ in the PAD population $[29,30]$. Seventeen patients achieved an MCID for PFWD during the lockdown period, and 6 achieved an MCID for 6MWD. No variables were retained in the model for 6MWD; otherwise, a significant model was observed for PFWD $\left(R^{2}=0.10 ; p=0.039\right)$ with the question "did your cohabitant exercise with you" showing a favorable odds ratio of 4.68 (95\% CI 1.09-20.20).

Finally, cardiovascular risk factors, other comorbidities, age, PAD severity by ABI, cultural level, sex and marital status were not included in any model.

\section{Discussion}

The study confirmed the hypothesis that a structured inhome exercise program was able to ensure adherence and maintain the mobility in a population of PAD patients restricted at home during the COVID-19 emergency.

At first, the study highlighted that in the absence of significant spontaneous physical activity, a structured program carried out at low-moderate intensity (3-4 METS) that was able to guarantee a minimum of 1000 steps per day, supported the walking ability of hypomobile patients.
Furthermore, this limited amount of activity performed inside the home in a corridor was associated to an acceptable control of risk factors, including body weight, blood pressure and diabetes.

The precise prescription allowed to counteract the progressive decline of mobility [24] and to maintain functional stability in the whole population, with functional improvement in PAD patients who started rehabilitation immediately before the lockdown and with maintenance of the mobility level among the Veterans. If in the program, early significant aerobic adaptations occur in the most ischemic muscles by walking even in confined spaces [28, 31], progressive further adaptations necessary to complete the functional recovery are favored by patient's spontaneous activity. In Veterans, in absence of this stimulus during the lockdown, the program favored the persistence of the benefits previously achieved. The hemodynamic parameters also showed a similar pattern (slightly improved or stable), confirming previous observations [6, 26, 32].

Interestingly, patients with more severe claudication prelockdown showed more favorable functional improvements, which may not regularly be observed following treadmillbased supervised programs [2].

The response was instead not different by sex, cultural level, marital status, comorbidities, type of house (flat or house with garden and courtyard) and city or countryside living. As a matter of interest, some family members (14\%) also started the in-home walking program prescribed for their partners, and this proactive behavior was a factor correlated with functional improvements.

The adherence to the program during the lockdown period was high $(85 \%)$, even without intermediate visits and with only remote control, as previously tested in a large randomized trial among dialysis patients [23]. The 
dropout rate, consistent with previously published data [6], was slightly increased due to the fear of the contagion in a small sample of patients.

The characteristics of the program may also explain the global response to the training. Unlike home-based programs where patients are generally advised to walk at a self-selected pace or to maximal ischemic leg pain [8, $32,33]$, this program is performed at a lower speed for short bouts in the absence of ischemic pain $[5,6,26]$. These facts facilitate execution in limited spaces and favor adherence. Finally, only a metronome for maintaining the prescribed walking cadence, a stop-watch, a corridor and a chair to sit in during the resting phase are required.

\section{Conclusion}

The study aimed to report a particular rehabilitative experience in a group of PAD patients during this historical period. The Ti-To home-based program, designed to overcome the barriers to exercise in an area with an aging index almost double the Europe mean value [19, 34], simply relying on the telephonic monitoring passed the test during the COVID-19 epidemic. Even if social frailty, i.e., reduced connections to society and little social activity, may be correlated with reduced physical function [35, 36], the program was able to ensure stable or improved function in a population with disability that was exposed to strict movement restrictions. However, the reduced sample size is a limitation of this observation.

Considering that resilient care systems should be identified to protect vulnerable patients [37], this program may represent a facilitated way to carry out regular and safe structured exercise activities to frail subjects, even with telephone support only, regardless of the type of home, atmospheric conditions or epidemic limitations.

\footnotetext{
Author contributions FM, SS, RM, ADG, VG, PZ and NL contributed to the conception or design of the work. FM, RM and NL contributed to the acquisition, analysis, or interpretation of data for the work. FM, RM and NL drafted the manuscript. SS, ADG, VG, PZ critically revised the manuscript. All gave final approval and agree to be accountable for all aspects of work ensuring integrity and accuracy.
}

Funding This research received no specific grant from any funding agency in the public, commercial, or not-for-profit sectors.

Data availability The dataset analyzed during the current study is publicly available in the Mendeley repository, https://doi.org/10.17632/ kdgj4rrhdr.1.

\section{Compliance with ethical standards}

Conflict of interest The authors declare that they have no conflict of interest.

Ethics approval All procedures performed in studies involving human participants were in accordance with the ethical standards of the institutional and/or national research committee and with the 1964 Helsinki Declaration and its later amendments or comparable ethical standards. The study was approved by the Ethics Committee CE-AV (n. 539/2020).

Consent to participate Informed consent was obtained from all individual participants included in the study.

Consent for publication Not applicable.

Code availability (software application or custom code) Not applicable.

\section{References}

1. Benjamin EJ, Muntner P, Alonso A, Bittencourt MS, Callaway CW, Carson AP, Chamberlain AM, Chang AR, Cheng S, Das SR et al (2019) Heart disease and stroke statistics-2019 update: a report from the American Heart Association. Circulation 139(10):e56-e528. https://doi.org/10.1161/CIR.0000000000 000659 ((Published correction appears in Circulation. 2020 Jan 14;141(2):e33))

2. Treat-Jacobson D, McDermott MM, Bronas UG, Campia U, Collins TC, Criqui MH, Gardner AW, Hiatt WR, Regensteiner JG, Rich K et al (2019) Optimal exercise programs for patients with peripheral artery disease: a scientific statement from the American Heart Association. Circulation 139(4):e10-e33. https://doi. org/10.1161/CIR.0000000000000623

3. Hageman D, Fokkenrood HJ, Gommans LN, van den Houten MM, Teijink JA (2018) Supervised exercise therapy versus home-based exercise therapy versus walking advice for intermittent claudication. Cochrane Database Syst Rev 4(4):CD005263. https://doi. org/10.1002/14651858.CD005263.pub4 ((Published 2018 Apr 6))

4. Proietti M (2020) Management of peripheral arterial disease in the modern era: an internist "Cup of Tea." Intern Emerg Med 15(2):195-197. https://doi.org/10.1007/s11739-019-02236-8

5. Manfredini F, Malagoni AM, Mascoli F, Mandini S, Taddia MC, Basaglia N, Manfredini R, Conconi F, Zamboni P (2008) Training rather than walking: the test in -train out program for home-based rehabilitation in peripheral arteriopathy. Circ J 72(6):946-952. https://doi.org/10.1253/circj.72.946

6. Malagoni AM, Vagnoni E, Felisatti M, Mandini S, Heidari M, Mascoli F, Basaglia N, Manfredini R, Zamboni P, Manfredini F (2011) Evaluation of patient compliance, quality of life impact and cost-effectiveness of a "test in-train out" exercise-based rehabilitation program for patients with intermittent claudication. Circ J 75(9):2128-2134. https://doi.org/10.1253/circj.cj-10-1311

7. McDermott MM, Domanchuk K, Liu K, Guralnik JM, Tian L, Criqui MH, Ferrucci L, Kibbe M, Jones DL, Pearce WH, Zhao L, Spring B, Rejeski WJ (2012) The Group Oriented Arterial Leg Study (GOALS) to improve walking performance in patients with peripheral arterial disease. Contemp Clin Trials 33(6):1311-1320. https://doi.org/10.1016/j.cct.2012.08.001

8. Gardner AW, Parker DE, Montgomery PS, Blevins SM (2014) Step-monitored home exercise improves ambulation, vascular function, and inflammation in symptomatic patients with 
peripheral artery disease: a randomized controlled trial. J Am Heart Assoc 3:e001107. https://doi.org/10.1161/JAHA.114.00110 7

9. McDermott MM, Spring B, Berger JS, Treat-Jacobson D, Conte MS, Creager MA, Criqui MH, Ferrucci L, Gornik HL, Guralnik JM et al (2018) Effect of a home-based exercise intervention of wearable technology and telephone coaching on walking performance in peripheral artery disease: the HONOR randomized clinical trial. JAMA 319(16):1665-1676. https://doi.org/10.1001/ jama.2018.3275

10. Italian Government. Ulteriori disposizioni attuative del decretolegge 23 febbraio 2020, n. 6, recante misure urgenti in materia di contenimento e gestione dell'emergenza epidemiologica da COVID-19, applicabili sull'intero territorio nazionale. (20A01807). Gazzetta Ufficiale. Serie Generale, n. 76 del 22 marzo 2020)

11. Health Alert: US Embassy Rome, Italy, March 10, 2020. https:// it.usembassy.gov/health-alert-u-s-embassy-rome-italy-march-102020/. Accessed 15 July 2020

12. Grasselli G, Pesenti A, Cecconi M (2020) Critical care utilization for the COVID-19 outbreak in Lombardy, Italy: early experience and forecast during an emergency response. JAMA 323(16):15451546. https://doi.org/10.1001/jama.2020.4031

13. https://it.usembassy.gov/covid-19-information/. Accessed 15 July 2020

14. COVID-19 Surveillance Group. Characteristics of COVID-19 patients dying in Italy: report based on available data on March 20th, 2020. Rome, Italy: Istituto Superiore di Sanità; 2020. https ://www.epicentro.iss.it/coronavirus/bollettino/Report-COVID -2019_20_marzo_eng.pdf. Accessed 15 July 2020

15. De Rosa S, Spaccarotella C, Basso C, Calabrò MP, Curcio A, Filardi PP, Mancone M, Mercuro G, Muscoli S, Nodari S et al (2020) Reduction of hospitalizations for myocardial infarction in Italy in the COVID-19 era. Eur Heart J 41(22):2083-2088. https ://doi.org/10.1093/eurheartj/ehaa409

16. Sena G, Gallelli G (2020) An increased severity of peripheral arterial disease in the COVID-19 era. J Vasc Surg 72(2):758. https ://doi.org/10.1016/j.jvs.2020.04.489

17. Mauro V, Lorenzo M, Paolo C, Sergio H (2020) Treat all COVID 19-positive patients, but do not forget those negative with chronic diseases. Intern Emerg Med 15(5):787-790. https://doi. org/10.1007/s11739-020-02395-z

18. Polosa R, Spinicci M, Prisco D (2020) "COVID-19: diagnosis, management and prognosis": a new topical collection of internal and emergency medicine. Intern Emerg Med 15(5):747-750. https ://doi.org/10.1007/s11739-020-02461-6

19. Varrella S (2020) Aging index in Italy 2019, by region. https:// www.statista.com/statistics/777225/ageing-index-by-region-initaly/. Accessed 15 July 2020 (Published by, Mar 23, 2020)

20. Lamberti N, Straudi S, Malagoni AM, Argirò M, Felisatti M, Nardini E, Zambon C, Basaglia N, Manfredini F (2017) Effects of low-intensity endurance and resistance training on mobility in chronic stroke survivors: a pilot randomized controlled study. Eur J Phys Rehabil Med 53(2):228-239. https://doi.org/10.23736 /S1973-9087.16.04322-7

21. Malagoni AM, Cavazza S, Ferraresi G, Grassi G, Felisatti M, Lamberti N, Basaglia N, Manfredini F (2016) Effects of a "test in-train out" walking program versus supervised standard rehabilitation in chronic stroke patients: a feasibility and pilot randomized study. Eur J Phys Rehabil Med 52(3):279-287

22. Malagoni AM, Catizone L, Mandini S, Soffritti S, Manfredini R, Boari B, Russo G, Basaglia N, Zamboni P, Manfredini F (2008) Acute and long-term effects of an exercise program for dialysis patients prescribed in hospital and performed at home. J Nephrol 21(6):871-878
23. Manfredini F, Mallamaci F, D’Arrigo G, Baggetta R, Bolignano D, Torino C, Lamberti N, Bertoli S, Ciurlino D, Rocca-Rey L et al (2017) Exercise in patients on dialysis: a multicenter, randomized clinical trial. J Am Soc Nephrol 28(4):1259-1268. https ://doi.org/10.1681/ASN.2016030378

24. McDermott MM, Liu K, Ferrucci L, Tian L, Guralnik JM, Liao Y, Criqui MH (2011) Greater sedentary hours and slower walking speed outside the home predict faster declines in functioning and adverse calf muscle changes in peripheral arterial disease. J Am Coll Cardiol 57(23):2356-2364. https://doi.org/10.1016/j. jacc.2010.12.038

25. Aboyans V, Ricco JB, Bartelink MEL et al (2018) 2017 ESC guidelines on the diagnosis and treatment of peripheral arterial diseases, in collaboration with the European Society for Vascular Surgery (ESVS): document covering atherosclerotic disease of extracranial carotid and vertebral, mesenteric, renal, upper and lower extremity arteries Endorsed by: the European Stroke Organization (ESO)The Task Force for the Diagnosis and Treatment of Peripheral Arterial Diseases of the European Society of Cardiology (ESC) and of the European Society for Vascular Surgery (ESVS). Eur Heart J 39(9):763-816. https://doi.org/10.1093/ eurheartj/ehx095

26. Lamberti N, Malagoni AM, Ficarra V, Basaglia N, Manfredini R, Zamboni P, Mascoli F, Manfredini F (2016) Structured homebased exercise versus invasive treatment: a mission impossible? A pilot randomized study in elderly patients with intermittent claudication. Angiology 67(8):772-780. https://doi.org/10.1177/00033 19715618481

27. Montgomery PS, Gardner AW (1998) The clinical utility of a six-minute walk test in peripheral arterial occlusive disease patients. J Am Geriatr Soc 46(6):706-711. https://doi. org/10.1111/j.1532-5415.1998.tb03804.x

28. Manfredini F, Lamberti N, Ficarra V, Tsolaki E, Straudi S, Zamboni P, Basaglia N, Gasbarro V (2020) Biomarkers of muscle metabolism in peripheral artery disease: a dynamic NIRSassisted study to detect adaptations following revascularization and exercise training. Diagnostics (Basel) 10(5):312. https://doi. org/10.3390/diagnostics 10050312

29. Bohannon RW, Glenney SS (2014) Minimal clinically important difference for change in comfortable gait speed of adults with pathology: a systematic review. J Eval Clin Pract 20(4):295-300. https://doi.org/10.1111/jep.12158

30. Lamberti N, López-Soto PJ, Guerzoni F, Napoli N, Gasbarro V, Zamboni P, Tsolaki E, Taddia MC, Rodríguez-Borrego MA, Manfredini R, Basaglia N, Manfredini F (2020) Changes in exercise capacity and risk of all-cause mortality in patients with peripheral artery disease: a 10-year retrospective cohort study. Intern Emerg Med 15(2):289-298. https://doi.org/10.1007/s11739-019-02176-3

31. Manfredini F, Malagoni AM, Mandini S, Felisatti M, Mascoli F, Basaglia N, Manfredini R, Mikhailidis DP, Zamboni P (2012) Near-infrared spectroscopy assessment following exercise training in patients with intermittent claudication and in untrained healthy participants. Vasc Endovasc Surg 46(4):315-324. https ://doi.org/10.1177/1538574412443318

32. McDermott MM, Liu K, Guralnik JM, Criqui MH, Spring B, Tian L, Domanchuk K, Ferrucci L, Lloyd-Jones D, Kibbe M, Tao H, Zhao L, Liao Y, Rejeski WJ (2013) Home-based walking exercise intervention in peripheral artery disease: a randomized clinical trial. JAMA 310(1):57-65. https://doi.org/10.1001/ jama.2013.7231

33. Gardner AW, Parker DE, Montgomery PS, Scott KJ, Blevins SM (2011) Efficacy of quantified home-based exercise and supervised exercise in patients with intermittent claudication: a randomized controlled trial. Circulation 123(5):491-498. https://doi. org/10.1161/CIRCULATIONAHA.110.963066 
34. Preedy VR, Watson RR (2010) Aging Index. Handbook of disease burdens and quality of life measures. Springer, New York. https:// doi.org/10.1007/978-0-387-78665-0_5051

35. Makizako H, Shimada H, Tsutsumimoto K, Lee S, Doi T, Nakakubo S, Hotta R, Suzuki T (2015) Social frailty in community-dwelling older adults as a risk factor for disability. J Am Med Dir Assoc 16(11):1003.e7-1003.e11. https://doi.org/10.1016/j. jamda.2015.08.023

36. Makizako H, Shimada H, Doi T, Tsutsumimoto K, Hotta R, Nakakubo S, Makino K, Lee S (2018) Social frailty leads to the development of physical frailty among physically non-frail adults: a four-year follow-up longitudinal cohort study. Int J Environ Res Public Health 15(3):490. https://doi.org/10.3390/ijerph15030490
37. Mureddu GF, Ambrosetti M, Venturini E, La Rovere MT, Mazza A, Pedretti R, Sarullo F, Fattirolli F, Faggiano P, Giallauria F, Vigorito C, Angelino E, Brazzo S, Ruzzolini M (2020) Cardiac rehabilitation activities during the COVID-19 pandemic in Italy. Position paper of the AICPR (Italian Association of Clinical Cardiology, Prevention and Rehabilitation). Monaldi Arch Chest Dis. https://doi.org/10.4081/monaldi.2020.1439

Publisher's Note Springer Nature remains neutral with regard to jurisdictional claims in published maps and institutional affiliations. 